\title{
A violência da vigilância: discursos sobre tecnologia na série You ${ }^{1}$
}

\section{The violence of vigilance: views on technology in the tv series You}

Júlia C. Versiani dos Anjos²

1 Uma versão anterior deste trabalho foi apresentada no GP Comunicação e Cultura Digital no $42^{\circ}$ Congresso Brasileiro de Ciências da Comunicação (Intercom).

2 Doutoranda do Programa de Pós-Graduação em Comunicação e Cultura da Universidade Federal do Rio de Janeiro (ECO-UFRJ). Mestre pela mesma instituição, com bolsa Capes, tendo defendido dissertação sobre discurso de ódio antifeminista nas redes sociais. Atualmente, é bolsista do CNPq com projeto de pesquisa sobre feminicídio na mídia e integrante do Núcleo de Estudos de Mídia, Emoções e Sociabilidade (Nemes). E-mail: julianjos@gmail.com. 


\section{Resumo}

O presente artigo analisa os sentidos expressos na produção televisiva You acerca de temas como interações digitais, vigilância e privacidade. A ficção seriada em questão contribui para que se possa ir além da visão simplista de oposição entre mundo real e virtual e, assim, discutir os problemas efetivamente existentes em torno do uso das tecnologias em nossa sociedade: a invasão de privacidade e a vigilância constante a que não apenas a protagonista feminina da série está submetida, mas também, guardadas as devidas proporções, todos os bilhões de usuários dos sites de redes sociais, que se divertem e se expressam por meio dessas ferramentas enquanto seus dados são explorados.

Palavras-chave

Tecnologia, vigilância, privacidade, gênero, séries de televisão.

\section{Abstract}

This paper aims to analyze the views expressed in the television show You on topics such as digital interactions, surveillance and privacy. The series in question helps to take the discussion beyond the simplistic view of opposition between the real and virtual world and, thus, address the problems that actually exist around the use of technologies in our society: the invasion of privacy and the constant surveillance that not only the female protagonist of the series is submitted, but also, with due proportions, all the billions of social media users, who have fun and express themselves through these tools while their data is exploited.

\section{Keywords}

Technology, vigilance, privacy, gender, tv series. 
Joe Goldberg, protagonista da série You, não tem perfil público em sites de redes sociais. Em seu primeiro encontro com Guinevere Beck, a garota que ele está tentando conquistar, Joe justifica essa decisão dizendo que é "um cara à moda antiga", que gosta da "vida real". Sua personalidade, a princípio, parece corroborar esse discurso exterior: Joe é um simpático gerente de livraria, grande conhecedor dos clássicos da literatura, além de namorado romântico e dedicado. Conforme o espectador acompanha a trajetória desse homem tão cultivado e obsequioso para conquistar o coração de sua donzela, porém, assiste enquanto ele rastreia cada passo da vida de Beck, descobre todos os seus segredos, comete assassinatos e termina por deter a namorada em cativeiro - todos esses crimes, ele realizou com ajuda das ferramentas de redes sociais.

A tecnologia, portanto, se tornou grande aliada de Joe e, segundo o produtor executivo da série, Greg Berlanti, chegou a funcionar como um personagem da trama ${ }^{3}$. A narrativa aqui analisada, desse modo, pode ser percebida como um enunciado historicamente situado, isto é, que demonstra preocupações e receios intrinsecamente relacionados ao entorno social e que "fornece ambientes ficcionais onde constelações de poder historicamente específicas se tornam visíveis" (SHOHAT; STAM, 2014, p. 102).

Partindo dessa noção, procuro perceber os sentidos expressos na produção sobre tecnologia, privacidade e vigilância por meio de uma análise do discurso de inspiração foucaultiana, que compreende enunciados como raridades: eles apenas existem em condições históricas muito específicas, que não se dão de forma necessária, mas através de mecanismos de poder e saber determinados (FOUCAULT, 2008). E o objetivo da investigação seria justamente compreender o princípio segundo o qual puderam aparecer esses conjuntos significantes e não quaisquer outros, além de desvelar as relações de poder e luta política que conformaram essa organização de mundo. No caso, analisarei cenas da série You 
que ilustram o que está em jogo na visão simplista de oposição entre mundo real e mundo virtual e desvelam as organizações de poder favorecidas por esses tipos de discursos de saber sobre a tecnologia.

\section{"Você é só você. Sem um pingo de falsidade": desconstruindo a oposição entre mundo "real" e "virtual"}

Os protagonistas da série You se conhecem em uma livraria: Beck está em busca de um livro e cabe a Joe, como funcionário do local, atendê-la e fechar a venda. Após esse momento, ele procura pelos perfis da moça em sites de redes sociais e se incomoda com a constante exposição de si que ela promove. Joe percebe, entretanto, que algo Beck não compartilhou com seus seguidores: o encontro dos dois na livraria - justamente um evento que ele considerou tão significativo. Ele, porém, logo se consola, pensando que o fato de a moça não ter mencionado esse momento nas redes apenas confirma que ele foi autêntico e importante; afinal, conclui Joe, sua vida on-line não é real.

Esse trecho da série retrata uma visão, muito presente no senso comum, de oposição entre as interações face-a-face, consideradas como conexões verdadeiras, "vida real", e a comunicação on-line, mediada por computador, reputada como "falsa", "artificial", sinal de decadência da sociedade e futilidade de seus adeptos. Como lembram Miller et al. (2016), esse tipo de comparação entre duas esferas implica que elas sejam excludentes e opostas uma em relação à outra. Em realidade, a pesquisa etnográfica dos autores demonstra que relações entre pessoas são criadas e mantidas através de interações tanto no ambiente on-line quanto no offline, de maneira integrada. A terminologia dualística e a ideia da internet como um "mundo separado", porém, permanecem modos através do quais pessoas ao redor do mundo compreendem e descrevem as próprias experiências comunicativas.

Ainda de acordo com Miller et al. (2016), colabora para a melhor compreensão desse tema o paradigma antropológico de que a utilização de mediações no contato entre indivíduos não é, de modo algum, exclusividade das sociedades contemporâneas urbanizadas - a intervenção da técnica também 
está presente até mesmo em uma sociedade tribal das mais isoladas. Além disso, tanto nos Estados Unidos quanto em uma ilha no meio do Oceano, as interações face a face não ocorrem de maneira totalmente "genuína" e "autêntica", mas sim estão sempre perpassadas por regras sociais e culturais bastante detalhadas.

A análise de Goffman (2002) sobre interações sociais face-a-face também é interessante para refletir sobre o caráter profundamente complexo do cálculo que cada indivíduo faz, diariamente, ao manter uma conversação com outro, por mais simples que essa troca possa parecer. $O$ autor se volta justamente para o estudo da estrutura dos momentos em que as pessoas se encontram na presença física imediata umas das outras. Essas interações não ocorrem de maneira livre e espontânea, mas sim guiadas por diversas técnicas e recursos utilizados pelos indivíduos com o fim de estabelecer uma definição da situação favorável a seus objetivos. Na perspectiva do autor, os sujeitos dramatizam papeis e procuram controlar as impressões que os outros terão de si, na expectativa de evocar julgamentos favoráveis. Assim, os atores se adaptam aos diversos ambientes sociais que frequentam, de acordo com as características valorizadas em cada espaço. A chamada plateia e até mesmo estranhos que circundam a conversa, segundo Goffman (2002), também atuam para salvar o espetáculo, corrigindo rupturas que possam surgir, quando necessário.

A série You demonstra de maneira interessante como ocorre essa colaboração entre ator e público de uma cena social de modo a não quebrar as expectativas. Em determinado momento, o personagem Joe percebe uma disputa velada de poder entre duas amigas de Beck, e decide se aproveitar dessa rixa para afastar a namorada de seu grupo de amigas. Ele, porém, não intervém naquele momento, pois sabe que um confronto direto iria contra a definição da situação (uma reunião descontraída) e que isso afetaria a fachada de bom moço que construiu para si. Quando Joe eventualmente consegue causar um confronto entre o grupo, também não o faz de maneira direta, mas sim percebendo como se dá a dinâmica entre as mulheres e sugerindo a uma delas que publique na internet uma foto 
que desagradará a outra. As interações on-line, portanto, agem em conjunto a conflitos e estratégias de atuação das interações face a face.

Já quando a própria Beck conduz a narração da série, percebemos que, além de - como acusa Joe - "montar uma vida" nos sites de redes sociais, ela também manipula as impressões que pretende passar aos demais em diversos momentos de suas interações face a face. A jovem convive com amigas de uma classe social diferente da sua e se esforça para não parecer inferior, por exemplo, quando dá a uma delas um lenço de marca refinada, acima de suas possibilidades financeiras. Além disso, em sua relação com o pai e a madrasta, Beck constantemente procura guardar para si a raiva e o rancor que sente em relação aos dois, mantendo uma fachada polida e cortês, tanto nas trocas de mensagens eletrônicas quanto nas interações face a face.

Constatamos, assim, que a narrativa da produção confere tanto ao personagem masculino quanto ao feminino a habilidade de manejar suas atitudes e personas dependendo dos ambientes em que interagem e dos objetivos que desejam atingir. A principal diferença entre as manipulações de Beck e as de Joe não é que as dela ocorrem preferencialmente no ambiente on-line e as dele nas interações face a face, mas sim que, enquanto ela se sente uma fraude, profundamente culpada por não relevar sempre seus verdadeiros sentimentos, Joe não considera de modo algum seu comportamento como fingido, mas sim como uma prova de sua afeição à mulher amada.

Outro ponto da teoria de Goffman que lança uma nova luz às interações que ocorrem na série You é a questão da busca de informações a respeito do outro com quem se interage, necessária para bem definir a situação em que se encontram durante determinada interação face a face e saber o melhor modo de agir. Essa informação sobre o outro, porém, nem sempre está facilmente acessível somos, portanto, levados a buscar sinais no outro, como sua vestimenta, idade e atitude corporal.

A primeira cena da produção confere um interessante exemplo acerca desse fenômeno. No momento em que Beck entra na livraria administrada por 
Joe, o público ainda não conhece a jovem, e passa a saber mais sobre ela através do olhar do protagonista masculino. Ele analisa cada detalhe da vestimenta e do comportamento da moça para tentar depreender informações sobre ela:

Olá. Quem é você? Pelo seu jeito, uma estudante. Sua blusa é solta. Você não está aqui para ser cobiçada. Mas suas pulseiras fazem barulho. Você gosta de um pouco de atenção. Ok, caí na rede. Você procura por um livro. Ficção, de F a K. Bom, você não é a ninfa insegura padrão em busca de um Faulkner que nunca vai terminar. Bronzeada demais para Stephen King. Quem você vai comprar? (YOU, 2018, ep. 1, 00:23).

Assim, Joe estabelece uma definição da situação da interação com Beck antes mesmo que ela pronuncie sua primeira palavra para ele. É interessante a expressão utilizada pelo roteiro para dizer que o personagem se interessou por ela - "caí na rede" - pois demonstra certa passividade, como se ele fosse quase uma vítima da mulher, que o conquistou apenas com sua escolha de acessórios. $\mathrm{Na}$ verdade, percebemos um processo ativo por parte de Joe, que demonstra o que Goffman (2002) teoriza como assimetria no processo comunicacional: existem aspectos do comportamento expressivo não-governáveis pelo indivíduo, mas que são considerados pelos seus observadores. No caso aqui analisado, o protagonista masculino de You leva esse processo ao extremo, uma vez que, a partir de pequenos detalhes do comportamento da personagem feminina, Joe conclui que ela necessita de um salvador e que ele é a pessoa perfeita para preencher essa vaga.

Não é apenas com a personagem feminina, porém, que Joe faz julgamentos apressados a partir de primeiras impressões. Enquanto dialogava com Beck ainda no primeiro encontro, elogiando sua escolha de livro, ele aponta para outro cliente da loja, que andava pelo local com um exemplar do autor Dan Brown. Segundo o protagonista, aquele cliente procurava outro livro para comprar junto com o best-seller e, assim, não parecer alguém pouco inteligente. Esse comentário é o que ele compartilha com Beck mas, quando a série nos permite conhecer os pensamentos privados do personagem, ele se refere de maneira extremamente grosseira ao homem desconhecido. Ao atender o cliente, entretanto, Joe não 
deixa de modo algum transparecer esses pensamentos, na medida em que se comporta de maneira gentil, se despedindo com um "Tenha um bom dia, senhor!", emoldurado por um sorriso cortês.

Alguns espectadores da série chegaram a questionar o modo como a obra retrata de modo tão gentil o personagem masculino, que acaba por se revelar um sociopata. Esse comportamento, contudo, se encaixa perfeitamente ao de alguém que manipula com destreza os demais: Joe sabe definir com precisão sua fachada para cada tipo de interação. Goffman define como fachada "o equipamento expressivo de tipo padronizado intencional ou inconscientemente empregado pelo indivíduo durante sua representação" (GOFFMAN, 2002, p. 29). Essa categoria de fachada se torna relevante para contrastar à ideia dos perfis nas ferramentas on-line de redes sociais, considerados - tanto pelo personagem da série analisada quanto pelo senso comum - artificiais e falsos, em oposição a uma suposta manifestação verdadeira do indivíduo. A partir daí, podemos chegar a duas reflexões: a primeira é que, se existe um sujeito sólido e genuíno, ele também não está nas interações face a face; a segunda é que, se existe falseamento na conduta de indivíduos, as fotos encenadas de Instagram não são nossa maior preocupação.

Além dos pequenos atos de manipulação da impressão que causamos aos demais, Goffman (2002) destaca que a idealização é um importante aspecto dessa representação dos sujeitos-atores, isto é, a tendência a mostrar aos demais uma feição melhorada de nós mesmos. É interessante contrastar essa afirmação ao discurso acusatório sobre a internet, em relação à falsidade das vidas aparentemente perfeitas que os usuários demonstram no ambiente online - e, novamente, a sociologia nos mostra que tal comportamento não é, de modo algum, exclusividade do Instagram. Goffman (2002) menciona o hábito de muitas famílias de se alimentarem com frugalidade no dia a dia, ao passo que preparam fartos e opulentos jantares ao receberem convidados. A representação idealizada seria até mesmo uma obrigação em certas profissões - o médico, por exemplo, precisa não apenas ser mas também parecer sempre limpo e higiênico. 
Tal comportamento, é importante ressaltar, não apresenta caráter desviante da normalidade, mas sim se constitui como uma espécie de homenagem aos valores oficiais comuns da sociedade. Em outras palavras, as pessoas apenas se esforçam para se apresentar de certa maneira considerada ideal porque comungam com as regras que definem esse comportamento como positivo. Não existe, nesse ato de representação, uma anomia social, como se costuma pensar no senso comum.

O usuário que interage nos sites de redes sociais, desse modo, não deve ser visto simplesmente como manipulado e nem manipulador, mas sim um sujeito social e estratégico. A crença de que as ferramentas de redes sociais meramente afastam as pessoas não se sustenta diante de uma análise do comportamento de seus usuários, uma vez que essas são comumente utilizadas tanto para se relacionar com alguém novo quanto para manter relações íntimas. O ambiente online confere, na verdade, maiores possibilidades para interação, na medida em que diversas plataformas permitem diferentes formas de contato, além de conversações síncronas ou assíncronas entre participantes afastados geograficamente.

No lugar de mundos separados, a melhor alternativa seria olhar para o ambiente on-line e o offline como dois quadros de referências complementares, que se combinam para formatar uma imagem mais completa de um indivíduo e suas relações. Nesse sentido, Miller et al. (2016) desenvolvem o conceito de uma "sociabilidade escalável", isto é: o espectro de relações de uma pessoa nos sites de redes sociais possui uma gradação, podendo ser menos ou mais intenso ou íntimo. Nessa perspectiva, a distinção simplista entre "mundo real" e "mundo virtual" é substituída por uma visão mais complexa que considera as diferentes dimensões e os diversos ambientes onde se dá uma gradação de relacionamentos.

Outro conceito interessante para melhor compreender essa atuação de um usuário estratégico é a ideia de polimídia (MADIANOU \& MILLER, 2013). Os autores defendem a existência de um ambiente de oportunidades comunicativas que funciona como uma estrutura integrada, isto é, em que cada meio é observado em relação aos demais. Assim, nesse ambiente, os usuários escolhem, de maneira estratégica, os meios que são, por suas características de usabilidade, mais 
propícios para cada tipo de comunicação que planejam estabelecer e exploram diferenças entre esses meios de acordo com as distinções que desejam realizar em suas relações pessoais. Por exemplo, em seu estudo etnográfico, os autores observaram que estudantes que vivem longe de casa costumam comunicar-se com seus pais por e-mail, já que esse meio não exige uma resposta rápida e lhes confere mais controle sobre a comunicação.

Estratégia semelhante é utilizada para a construção narrativa da protagonista feminina da série You. Quando Joe pede seu número de telefone, ela diz que prefere se comunicar por e-mail. Ele percebe que ela toma essa atitude em uma tentativa de se resguardar, afinal eles mal se conhecem, e a conversa dos dois segue por correio eletrônico. Nesse ponto, porém, a trama apresenta uma virada: percebemos que Joe, na verdade, surrupiou o telefone celular da moça. Quando ela compra um aparelho novo, não se dá conta de que precisaria desconectar o antigo da "nuvem" e, assim, Joe segue tendo acesso a todos os seus dados e conversas.

Ainda assim, a narrativa abre espaço para que o personagem masculino seja surpreendido, em alguns momentos, por fatos que não estavam presentes nas conversas pessoais de Beck em seu telefone. Ao segui-la e escutar um diálogo da jovem com as amigas em um bar, o stalker fica sabendo que Beck teve um encontro sexual sem compromisso, na tentativa de esquecer um antigo relacionamento. É apenas nesse momento que Joe se dá conta de que Beck era uma usuária ativa do aplicativo de relacionamentos Tinder. Esse ponto da narrativa ajuda a compreender como a sociabilidade dos indivíduos contemporâneos não ocorre de forma linear, mas sim com diversas intermitências entre os ambientes on-line e offline, feitas de maneira consciente, de acordo com os tipos de relacionamentos que se deseja manter. Mesmo as interações no ambiente online não ocorrem de maneira estática, mas sim são fluidas e híbridas, isto é, "combinam diversos serviços digitais de comunicação julgados como mais adequados para a interação em dado momento e segundo certas condições" (PRIMO et al., 2017, p. 23).

No caso da série, a personagem feminina não divulgava detalhes sobre sua vida sexual em seus perfis do Facebook ou do Instagram, e tampouco em conversas 
virtuais com suas amigas. Como se trata de informações consideradas de caráter íntimo e que poderiam torná-la vítima de julgamentos mesmo por parte de pessoas próximas, ela apenas menciona o fato de passagem, em meio a uma conversa facea-face sobre outro assunto, após ter ingerido bebidas alcóolicas. Por meio dessa passagem, a série reproduz uma prática percebida por Miller et. al. (2016) em sua etnografia: as ferramentas de mídias sociais costumam reforçar a normatividade de gênero e acabam por exibir comportamentos mais conservadores do que os presentes na sociabilidade offline. Segundo os autores, "em contextos offline, mulheres e homens tendem a performar práticas e papeis mais variados (...), nas mídias sociais, tendem a aderir de maneira mais rígida às expectativas sociais sobre como deveriam se comportar" (MILLER et al., 2016, p. 126, tradução livre)4.

A protagonista feminina da série You, desse modo, é construída narrativamente de modo a fazer um uso estratégico das ferramentas de comunicação digital, manejando que informações sobre si deseja expor para aderir aos padrões de comportamento social, de maneira semelhante ao que realizamos cotidianamente em nossas interações face a face. Ela, entretanto, se enxerga como uma fingidora, acreditando na visão dualística entre "mundo real" e "mundo virtual", e se martirizando por não exibir a todos o que seria o seu "verdadeiro eu".

Essa reprovação de seu próprio comportamento aumenta quando ela começa a se relacionar com Joe, que, como foi dito, não possui perfil em sites de redes sociais e afirma "apreciar a vida real". Em determinado momento da narrativa, Beck compartilha sua angústia com o namorado, exaltando o comportamento dele, supostamente genuíno e louvável, em oposição ao seu próprio, visto como falso e fútil: "Você não está tentando ser quem não é. Você é só você. Sem um pingo de falsidade. (...) Você não se importa com coisas idiotas como postar sua vida online. É uma revelação. Sabe quantas selfies eu já tirei no vaso? Muitas" (YOU, 2018, ep. 4, 39:42). 
Logo depois dessa declaração, porém, quando Joe fica sozinho, ele se apressa em olhar o telefone antigo da namorada para examinar a conversa dela com as amigas. Alguns dias antes, Beck havia confidenciado, através desse diálogo, estar decepcionada com o parco desempenho sexual do namorado. Nesse momento, portanto, Joe deseja saber se vai, em suas palavras, "ganhar uma segunda resenha". Ele sabia que Beck tem, no celular, a possibilidade de estabelecer a qualquer momento "um ponto de encontro virtual para conversas privadas" (PRIMO et al., 2015, p. 529) e, na verdade, ansiava para que ela o fizesse, para que ele pudesse ter acesso a essa informação que ela não compartilhava com ele, mas sim com outras pessoas. Esse comportamento demonstra uma interessante ambiguidade na construção do personagem: apesar de dizer que o mundo virtual se opõe ao real e aceitar calado quando a namorada o elogia por supostamente não fazer uso das tecnologias digitais, Joe reconhece a importância da comunicação online como uma maneira de se relacionar com os demais de forma íntima e se utiliza dela para invadir essa intimidade que não Ihe diz respeito.

Outro ponto interessante dessa cena que pode ser melhor compreendido a partir da teoria sobre cibercultura é o fato de que Joe deseja receber uma "resenha", uma validação através de uma conversa mediada por um aparelho eletrônico. Ele, que se diz tão avesso a esse tipo de interação, fica feliz ao ver sua vida sexual comentada, mesmo que seja por meio de poucas palavras e alguns memes. No tópico a seguir, avaliarei a tendência a nos tornarmos, a partir das interações digitais, objetos de escrutínio a racionalização alheia, e discutirei como esse processo, na verdade, vai além das características da tecnologia, mas sim está intimamente ligado com um contexto social mais amplo.

\section{"Será que vou ganhar uma segunda resenha?": controle e racionalização das relações}

Gerlitz \& Helmond (2013) analisam que as ferramentas de redes sociais tornaram possível transformar intensas experiências afetivas e complexas dinâmicas sociais difíceis de medir em valores contáveis e facilmente comparáveis. 
O personagem da série analisada, como foi visto, não se incomoda com essa simplificação de um intenso momento íntimo, uma vez que está mais interessado em receber aprovação daquela que é seu objeto de desejo. É curioso perceber, portanto, o jogo realizado pela narrativa nesse momento: mesmo um personagem que constantemente enxerga os demais como objetos - como o protagonista da série, o qual assassinou duas pessoas, que ele via como "câncer", e perseguiu obsessivamente uma mulher - acaba por também se colocar como objeto, a ser esquadrinhado e avaliado.

De acordo com Turkle (2011), a vida conectada justamente encoraja todos nós a tratar os demais de modo semelhante ao qual manejamos objetos: de maneira arbitrária, sem dedicar muito pensamento, como se lidássemos com algo inanimado, sem muita importância e que pode ser descartado. Para a autora, isto acaba se passando de maneira natural, devido à grande quantidade de estímulos gerados pela tecnologia: mergulhados em centenas de e-mails, mensagens de texto e informações que a todo o momento chegam a nós em velocidade muito maior que a nossa capacidade de responder a essas demandas, acabamos por reduzir a importância de cada interação. Além disso, como escrevemos muitas vezes para centenas de "amigos" ao mesmo tempo, tendemos a tratar indivíduos como uma unidade, uma única audiência.

Mais interessante, porém, na teoria da autora para a análise aqui proposta é a observação de que o maior atrativo, para nós, na comunicação mediada pelas tecnologias é a facilidade de controlá-las e garantir que estejam sempre acessíveis e agradáveis. Se não mais satisfazem, podemos facilmente descontinuálas; se as apreciamos, podemos nos conectar sem restrições. Assim, o único fator a definir quando deixaremos a interação não é a ausência de conteúdo, mas sim nós mesmos, quando cansamos. Essa situação em que conveniência e controle são nossas prioridades ao nos relacionarmos com os demais, na visão de Turkle (2011), se constitui como um grave problema, uma vez que leva a uma simplificação e uma redução dos relacionamentos e faz com que esperemos mais da tecnologia e menos dos humanos. É justamente o modo 
como o protagonista da série You foi construído narrativamente: em seu discurso íntimo, ele se enxerga como amigo da tecnologia e espera pouco da maioria das pessoas, julgando-as como inferiores e até mesmo passíveis de eliminação. De seu interesse amoroso, por sua vez, ele espera demais, desejando que, assim como a tecnologia, Beck esteja sempre disponível, passível de controle e fornecendo prazer e alegria.

Outro aporte teórico para compreender esse processo contemporâneo de objetificação e racionalização do outro é fornecido pela socióloga Eva Illouz (2007). A autora, porém, inverte a ordem das preocupações de Turkle, ao demonstrar que a tendência à racionalização dos relacionamentos, ainda que tenha na internet uma potente forma de expressão, se desenvolve por diversos fatores bem anteriores ao surgimento da world wide web. A comunicação mediada por computadores, sob essa ótica, não é vista como a grande vilã, mas sim como uma das instituições que estão intimamente ligadas em um processo de mercantilização da individualidade, ao lado da literatura de autoajuda, da indústria de conselhos, do Estado e das indústrias farmacêuticas, entre outros.

Illouz (2007) localiza esse fenômeno dentro do que chama de "capitalismo emocional", uma cultura em que discursos emocionais e econômicos se moldam mutuamente, de modo que a dimensão afetiva se torna um aspecto essencial do comportamento econômico e a vida emocional, por sua vez, passa a seguir a lógica das relações econômicas. Nas palavras da autora: "Se a esfera da produção coloca o afeto no centro dos modelos de sociabilidade, as relações íntimas colocam cada vez mais em seu centro um modelo político e econômico de barganha e troca" (ILLOUZ, 2007, p. 27, tradução livre) 5 .

Nesse cenário de um capitalismo emocional, segundo a autora, estaria inserido um vasto processo de racionalização das relações íntimas, no qual emoções e relações complexas "são transformados em objetos mensuráveis e calculáveis, 
a serem capturados em declarações quantitativas" (ibid., p. 24, tradução livre) ${ }^{6}$. Illouz fornece como exemplo para esse fenômeno a popularização de questionários, publicados em revistas, para avaliar o quão compatível um casal é. Um desses questionários avaliados pela autora chegou a contar com 60 perguntas, desenvolvidas por um psicólogo, que levavam os respondentes a escrutinar detalhes de suas vidas. Segundo a publicação em questão, a pontuação ideal seria entre 220 e 300 pontos, que indicariam um nível suficientemente alto de atração romântica capaz de sustentar um relacionamento. A complexidade de saber se uma relação é ou não benéfica se encontra, nesse caso, reduzida a selecionar algumas frases em um teste de múltipla escolha. Situações íntimas são transformadas em "pontos" que o casal deve "acumular" para ganhar o rótulo de "compatível".

É interessante observar como elementos desse fenômeno apontado por Illouz aparecem na série analisada. O protagonista masculino proclama a todo momento estar ajudando a amada a se livrar de pessoas que não a respeitam e não a valorizam, uma vez que ela supostamente não consegue avaliar por si própria quem devem ser suas companhias - em determinado momento, ele chega a afirmar: "sou o maior feminista que você conhece". Sob a ótica de Joe, ele estaria conferindo à namorada inúmeras vantagens que, para usar o vocabulário econômico, gerariam um superávit para o relacionamento mesmo quando descontados o que ele vê como pequenos inconvenientes. Esse relacionamento seria o ideal para a moça, uma vez que ele estaria cuidando dela todo o tempo, com o objetivo de que ela "florescesse" e realizasse seu sonho de se tornar uma escritora renomada. O problema, obviamente, é que esse "cuidado" envolve não apenas cozinhar e lavar as roupas da amada, mas também vigilância constante, invasão de privacidade e até assassinato.

A construção do personagem masculino é feita de modo a revelar um comportamento obsessivo e violento desde os primeiros momentos da narrativa nos primeiros 10 minutos de série, Joe já havia descoberto onde Beck morava e a 
observava escondido; antes de o episódio piloto marcar 30 minutos, ele invadiu o apartamento dela e afanou alguns de seus pertences; ao final do segundo episódio, ele assassinava um homem que via como seu concorrente pelas afeições da moça, após mantê-lo encarcerado por dias. Ainda assim, alguns espectadores da série relataram sentir empatia e atração em relação a Joe Goldberg, e torcer para que ele e sua amada ficassem juntos ${ }^{7}$. Mas como é possível amar um stalker?

No próximo tópico, desenvolverei argumentação no sentido de que, ao utilizar ferramentas de redes sociais, estamos todos, de certa maneira, acordando, dormindo, vivendo e nos divertindo ao lado de um stalker. Em determinado momento da série You, Joe afirma para Beck que ela deve perdoá-lo pelo que ele fez, já que tudo foi para que ela tivesse uma vida melhor. Essa frase lembra assustadoramente o argumento dos sites que desejam que aceitemos os chamados "cookies" ou o compartilhamento de dados de navegação - eles alegam que tudo é feito pensando em uma melhor experiência para nós mesmos.

\section{A redoma de vidro: privacidade e vigilância}

"Aí está você. Todas as contas abertas. Você quer ser vista, ouvida, conhecida. Eu acabei sendo forçado a cooperar": esse é o discurso de Joe quando decide buscar informações sobre Beck e encontra diversos dados acessíveis on-line. O stalker obviamente não questiona a legitimidade de suas próprias ações ao vasculhar a vida pessoal de alguém através da internet, enquanto afirma ser um cara totalmente alheio às redes sociais on-line. Em vez disso, ele culpa a própria Beck por seduzilo, primeiro com suas pulseiras que fazem barulho quando ela entra em sua loja, depois com a divulgação de informações sobre si nos meios digitais.

Nesse momento, além da culpabilização da vítima, o protagonista masculino da série também corrobora com mais uma visão muito recorrente no senso comum: a de que aqueles que compartilham informações sobre sua vida privada

Mais informações em: https://entretenimento.uol.com.br/noticias/redacao/2019/01/11/voce-penn-badgley-sepreocupa-com-fas-apaixonadas-pelo-stalker-joe.htm e https://capricho.abril.com.br/famosos /penn-badgley-pedepara-fas-nao-defenderem-seu-personagem-na-serie-voce/. Acesso em: 28 jun. 19. 
em ferramentas de redes sociais não se importam com sua privacidade e não podem reclamar da invasão dessa. Segundo Boyd e Marwick (2011), essa crença parte de uma visão dicotômica sobre privacidade como absolutamente oposta ao ambiente público. Assim, só teriam direito à proteção aquelas informações mantidas no âmbito doméstico e íntimo. É preciso considerar, também, uma questão geracional: adultos tendem a pensar em suas casas como o espaço mais privado possível, enquanto adolescentes rejeitam essa noção e não consideram o lar como um local onde gozam de privacidade, mas sim como espaço no qual estão sob constante olhar e poder paterno.

Além disso, Vaidhyanathan (2011) acrescenta que a preocupação com privacidade não se limita a um desejo por reter informações sobre si, mas tem maior relação com a vontade de controlar nossas reputações. Assim, quando um jovem divulga um detalhe de sua vida pessoal para sua rede de amigos online, não quer dizer que ele está abrindo mão de sua privacidade, mas sim dirigindo a disseminação de informação sobre si em um contexto no qual ele pensa estar seguro e em controle.

Como lembram Boyd e Marwick, jovens costumam desenvolver intricadas estratégias para tentar garantir que compartilham conteúdo apenas com aqueles que realmente desejam e, desse modo, demonstram que, sim, ainda se importam com privacidade. Nesse sentido, não é contraditório o fato de que eles queiram ser vistos, reconhecidos e validados, mas apenas por certas pessoas.

O problema se inicia quando a maioria dos ambientes de interação online é propositalmente desenhada para favorecer o espraiamento de dados e dificultar um manejo mais consciente destes. A confusão e falta de consciência sobre os limites do compartilhamento de informações se convertem em lucros para as companhias que criaram esses ambientes (VAIDHYANATHAN, 2011).

É interessante, para a questão, pensar sobre o caso do Facebook. Apesar dos esforços que Mark Zuckerberg afirma fazer para tornar sua ferramenta um local mais seguro para seus usuários, Vaidhyanathan (2018) defende que qualquer ação nesse sentido será apenas cosmética, mas não atingirá a raiz da questão. Segundo o 
autor, o problema do Facebook é o Facebook - afinal, se trata de um sistema global que conecta mais de 2 bilhões de pessoas de diversos locais do planeta, permite que todas elas publiquem conteúdo sem análise prévia da ferramenta, desenvolve algoritmos que favorecem assuntos polêmicos e lucra a partir de um sistema de publicidade que direciona anúncios utilizando vigilância massiva e elaborados dossiês pessoais dos usuários. Além disso, a empresa comprou diversos de seus potenciais competidores, como Instagram e Whatsapp e, assim, não possui grandes concorrentes como um conector de pessoas on-line. Nas palavras do autor:

O Facebook é grande demais, poderoso demais e intrusivo demais e funciona muito bem - para que uma reforma superficial faça diferença. Todos os problemas que o Facebook amplificou foram intensificados porque o Facebook funcionava exatamente como deveria funcionar (VAIDHYANATHAN, 2018, p. 9-10, tradução livre) ${ }^{8}$.

O autor afirma, ainda, que a ferramenta é, ao mesmo tempo, um sistema de prazer e um sistema de vigilância - ambos os aspectos não podem ser separados. O Facebook é manipulador, no sentido de que cada aspecto de seu desenho é cuidadosamente desenvolvido para nos manter conectados o máximo de tempo possível e, a partir daí, vigiar nossos passos: "O Facebook nos atrai, nos prende, nos encoraja a declarar nossas afiliações, nos divide e acompanha todas as interações ao longo do caminho" (VAIDHYANATHAN, 2018, p. 51).

Os sites de redes sociais se tornam, desse modo, um sistema de vigilância diferente de qualquer coisa que já tenhamos visto, e para o qual não estamos preparados. As configurações padrão dos perfis de Facebook e Instagram favorecem não os usuários, mas as próprias ferramentas. As empresas alegam nos fornecer escolhas para modificar nossas configurações de privacidade, porém protegê-la não deveria ser uma preocupação individual - feita a partir de muito esforço para entender as evasivas políticas de privacidade e mudar uma a uma as configurações - 
mas sim uma responsabilidade da empresa. Esse não é, entretanto, o seu interesse, uma vez que o negócio do Facebook é justamente vender informações de seus usuários a anunciantes. A corporação de Zuckerberg, ao lado do Google, possui tanto quantidade quanto riqueza de dados sobre seus clientes de maneira jamais sonhada por outras companhias. Seus sistemas são desenvolvidos em favor do máximo acúmulo, exposição e disponibilidade de informações, doa a quem doer (VAIDHYANATHAN, 2011; 2018).

De fato, o nível de dados publicado a cada segundo nessas ferramentas é tão gigantesco que, caso o Facebook e o Google realmente desejassem tomar uma atitude mais cuidadosa com a privacidade dos usuários e evitar o compartilhamento de conteúdo ofensivo, seriam necessárias grandes mudanças como o requerimento de um período de avaliação antes da publicação de fotos, por exemplo. Assim, alerta Vaidhyanathan (2018), em favor da "experiência do usuário", ficam em risco a saúde e a segurança de alguns, enquanto os verdadeiros benefícios vão para essas corporações.

Outra particularidade do Facebook e do Google é a grande assimetria de poder existente entre empresa e usuários. Como analisa Vaidhyanathan (2011), a vigilância feita nesses casos vai além do modelo do panóptico, de visibilidade e controle social. Diferente dos prisioneiros do modelo arquitetado por Bentham, a maioria das pessoas não têm consciência de todos os modos pelos quais está sendo vigiada. Assim, o autor defende que uma metáfora mais precisa seria a da caixa preta, que contém diversas informações sobre nós, mas cujos mecanismos são inacessíveis. Não existe reciprocidade, prestação de contas ou consistência - as regras mudam a qualquer momento e, se é que compreendemos quais mudanças estão sendo feitas, não podemos opinar.

A série You pode fornecer, ainda, outra metáfora para o tipo de vigilância a que estamos submetidos por meio dos sites de redes sociais: a cela transparente no porão da livraria de Joe, onde ele prendeu Beck quando ela descobriu toda a verdade sobre ele. Joe alegava que ela precisava de tempo para pensar e concluir que ele havia feito tudo para o bem dela e, enquanto isso, ele tentaria tornar aquela 
redoma de vidro o mais confortável possível para sua amada, deixando algumas resmas de papel para que ela escrevesse, trazendo uma colcha confortável para esquentá-la e até mesmo preparando seu café da manhã preferido. "Veja isso como uma oportunidade!", disse Joe.

Depois de algum tempo presa, Beck, escreve um texto emocionado, no qual se questiona: "Agora, em seu castelo, você entende que o príncipe encantado e barba azul são o mesmo homem e você não ganha um final feliz a não ser que ame os dois. Você não queria isso? Ser amada?" (YOU, 2018, ep. 10, 22:40). O dilema enfrentado por ela, guardadas as devidas proporções, espelha a questão que se coloca diante dos usuários de sites de redes sociais: se queremos usufruir dos benefícios do Facebook ou do Instagram, isso significa que somos obrigados a aceitar a vigilância constante da vida em uma redoma de vidro?

\section{Observações finais}

Neste artigo, a proposta foi analisar os sentidos expressos na série You acerca de temas como interações digitais, vigilância e privacidade. A produção televisiva em questão contribui para que se possa ir além da visão simplista de oposição entre mundo real e virtual, uma vez que demonstra que interações face-a-face não são completamente genuínas e livre de cálculo como se costuma pensar, enquanto a comunicação on-line não é simplesmente ditada por manipulações e sujeitos antissociais, mas sim por atores sociais estratégicos que empregam diferentes meios com o objetivo de administrar relacionamentos de variados graus de intimidade.

Ainda que a protagonista feminina da série critique a si mesma pelo ato de tirar selfies no vaso, o verdadeiro problema que permeia toda a sua narrativa é a invasão de privacidade sofrida por ela e a vigilância constante a que ela estava submetida sem estar ciente disto, tudo graças à Joe e sua "cúmplice", a tecnologia. Essa história se torna real para centenas de mulheres diariamente, e também serve como ponto de partida para a reflexão de todos os bilhões de usuários dos sites de redes sociais, que se divertem por meio dessas ferramentas e se sentem atraídos pela aparente possibilidade de controle, sem a consciência 
do modo como seus dados são explorados. Soma-se a isto o vasto processo de racionalização das relações íntimas que se desenrola nos últimos tempos, em meio a um contexto de capitalismo emocional (ILLOUZ, 2007), no qual a vida emocional passa a seguir a lógica das relações econômicas. Seguimos, entretanto, culpando meras fotos encenadas de influencers digitais como o principal lado negativo do Instagram e do Facebook.

Assim, do mesmo jeito que o arco narrativo de Beck dirige a personagem à conclusão de que o príncipe encantado e o stalker obsessivo eram o mesmo homem, somos levados à lembrança dolorosa de que as ferramentas de redes sociais são máquinas de prazer e, também, de vigilância. Mas, do mesmo jeito que Beck, devemos recordar, ainda, que não se trata de um estado natural e imutável das coisas. Nos últimos momentos da série, a protagonista desabafa: "Sabe o que eu acho? Que isso tudo foi uma desculpa para justificar se intrometer na vida de garotas e violá-las completamente. Acho que adora isso. O poder" (YOU, 2018, ep. 10, 40:49). Cabe a nós, agora, refletir sobre a melhor maneira de lidar com o stalker que vive em cada um dos telefones de nossos amigos e conhecidos e, também, é claro, no nosso próprio aparelho.

\section{Referências bibliográficas}

BOYD, D.; MARWICK, A. Social privacy in networked publics: teens' attitudes, practices, and strategies. In: A decade in Internet time: symposium on the dynamics of the Internet and society, 2011. Disponível em: https://papers.ssrn.com/sol3/ papers.cfm?abstract_id=1925128.

FOUCAULT, M. Arqueologia do saber. Rio de Janeiro: Forense Universitária, 2008.

GERLITZ, C.; HELMOND, A. The like economy: social buttons and the data-intensive web. New Media \& Society, v. 15, n. 8, 2013. 
GOFFMAN, E. A representação do eu na vida cotidiana. Petrópolis: Vozes, 2002.

ILLOUZ, E. Cold intimacies: the making of emocional capitalism. Cambridge: Polity Press, 2007

MADIANOU, M.; MILLER, D. Polymedia: towards a new theory of digital media in interpersonal communication. International Journal of Cultural Studies, v. 16, n. 2, 2013.

MILLER, D. ; COSTA, E. ; HAYNES, N. ; MCDONALD, T. ; NICOLESCU, R. ; SINANAN, J. ; SPYER, J.; VENKATRAMAN, S.; WANG, X. How the world changed social media. London: UCL Press, 2016.

PRIMO, A. T.; VALIATI, V.; LUPINACCI, L.; BARROS, L. Conversações fluidas na cibercultura. Revista Famecos, v. 24, n. 1, 2017.

PRIMO, A.; LUPINACCI, L.; VALIATI, V.; BARROS, L. Comunicação privada na internet: da invenção do particular na Idade Média à hiperexposição na rede. Revista Intexto, n. 34, 2015.

TURKLE, S. Alone together: why we expect more from technology and less from each other. New York: Basic Books, 2011.

SHOHAT, E.; STAM, R. Unthinking Eurocentrism: multiculturalism and the media. New York: Routledge, 2014.

VAIDHYANATHAN, S. Anti-social media: how Facebook disconnects us and undermines democracy. New York: Oxford University Press, 2018. 
. The Googlization of everything (and why should we worry). Los Angeles:

The University of California Press, 2011.

\section{Série}

YOU. Creators: Greg Berlanti e Sera Gamble. Netflix, 2018. Acesso em: 10 set. 20.

Submetido em: 3 jun. 20 | aprovado em: 23 set. 20 